\title{
Factors influencing calcification of cardiac bioprostheses in adolescent sheep
}

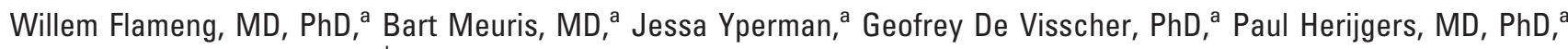 \\ and Erik Verbeken, $\mathrm{MD}, \mathrm{PhD}^{\mathrm{b}}$
}

From the Laboratory of Experimental Cardiac Surgery, Department of Cardiovascular Diseases, ${ }^{\mathrm{a}}$ and the Department of Pathology, ${ }^{\mathrm{b}}$ Katholieke Universiteit Leuven, Leuven, Belgium.

Received for publication July 25, 2005; revisions received Dec 11, 2005; accepted for publication Feb 6, 2006.

Address for reprints: Willem Flameng, MD, $\mathrm{PhD}$, CEHA, Provisorium I, Minderbroedersstraat 17, B-3000 Leuven, Belgium (E-mail: (willem.flameng@med.kuleuven.be).

J Thorac Cardiovasc Surg 2006;132:89-98

$0022-5223 / \$ 32.00$

Copyright $\odot 2006$ by The American Association for Thoracic Surgery

doi:10.1016/j.jtcvs.2006.02.036
Objective: We determined the possible effects of age, antimineralization treatments, circulatory implant conditions, prosthesis design, and valve-related structural aspects on valve calcification in adolescent sheep.

Methods: Calcium content was measured by means of atomic absorption spectrometry in bioprostheses implanted in 120 sheep (age $<1$ year) for a period of 3 or 6 months.

Results: Bioprostheses calcified significantly in adolescent sheep, but the extent of calcification was multifactorial. Multivariate analysis of the calcium content reveals that age, mitral or pulmonary implant position, prosthesis design (stented or stentless), structure (porcine or pericardial, wall portion or cusp), and antimineralization treatment are independent factors influencing calcification; implant duration beyond 3 months was not. In juvenile sheep (age 5 months) the wall portion, as well as the cusps of the prosthesis, calcified significantly more than in adolescent sheep (age 11 months). Irrespective of age, the cusps of valves implanted in the mitral position calcified more than those in the pulmonary position. The wall portion of stentless valves calcified more than that of stented valves, and pericardial valves calcified less than porcine valves. The surfactant (Tween 80, No-React, and $\alpha$-amino-oleic acid) and alcohol (ethanol and octanediol) treatment significantly reduced cusp calcification; sodium dodecylsulfate did not. None of the anticalcification treatments was able to prevent wall calcification in stentless porcine valves.

Conclusion: These findings suggest that tissue valve calcification is determined by many independent factors, which can be identified by using adolescent sheep as a prec linical in vivo model.

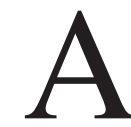
fter implanting more than 1500 heart valves in sheep over the years, Michael Jones at the National Heart, Lung, and Blood Institute developed the juvenile sheep model for testing biologic heart valves. ${ }^{1}$ Calcium content of the valves was detelrmined by means of atomic spectrometry after implantation for 20 weeks in the mitral or tricuspid position. The objective was to study various antimineralization treatments, and he found that there was a very wide distribution range of calcium content for each valve treatment as a function of individual animals. Therefore a large number of complete experiments are needed to determine the efficacy of a given treatment. In spite of the variability of the calcifications between animals and the inhomogeneity of the calcium deposits within the same valve, calcium content measurement with atomic absorption spectroscopy is still accepted as the gold standard. Alternative techniques are soft radiographic assessment of valve calcifications or histologic determination of calcium deposits in the valve tissue. How much the results of these techniques correlate with each other is unclear.

A problem with the use of juvenile animals is their growth potential: they still grow considerably, and a severe patient-prosthesis mismatch can occur. This could 


\section{Abbreviations and Acronyms}

AOA $=\alpha$-amino-oleic acid

KUL $=$ Katholieke Universiteit Leuven

SDS $=$ sodium dodecylsulfate be avoided by using adolescent or adult animals for valve testing. Unfortunately, little is known about accelerated calcification in these grown-up animals.

The aim of the present study was to evaluate accelerated calcification of bioprosthetic heart valves in adolescent sheep and to study the potential to differentiate between antimineralization treatments in this animal model. Therefore we studied the effect of age (juvenile vs adolescent), implant position (left or right side), implant duration ( 3 vs 6 months), valve tissue material (porcine aortic valve or bovine pericardium, aortic wall portion or cusps), valve design (stented or stentless), and antimineralization treatment on valve calcification.

\section{Materials and Methods}

All animals were cared for by a veterinarian in accordance with the "Guide for the care and use of laboratory animals" published by the National Institutes of Health (National Institutes of Health publication no. 85-23, revised 1985). The study was approved by the Ethics Committee of the Katholieke Universiteit Leuven (KUL). One hundred twenty-six female Lovenaar sheep, younger than 12 months of age and weighing between 29 and $63 \mathrm{~kg}$, were obtained from the Zoötechnical Center from the KUL and were quarantined at the animalium facility of the KUL before undergoing cardiac surgery.

\section{Valves Studied}

Fifteen different types of tissue valves were used in this study. The types and their major characteristics are presented in Table 1. All valves are aortic prostheses and are made by the following manufacturers: Medtronic, Inc, Minneapolis, Minn (Mosaic, Hancock MO, Hancock II, Hancock I pulmonary valved conduit, Freestyle aortic root); St Jude Medical, Inc, St Paul, Minn (Epic, Toronto SPV; Sulzer Carbomedics-Photofix); Labcor Laboratorios, Bela Horizonte, Brazil (Labcor, Labcor Duranol, Labcor pulmonary conduit); BioVascular, Inc, St Paul, Minn (Biocor genetic); Sorin Biomedica, Saluggia, Italy (Pericarbon stented, Pericarbon stentless); Edwards Lifesciences, Irvine, Calif (Prima plus, Perimount); Biocor Industria e Pesquisas Ltda, Belo Horizonte, Brazil (Biocor No-react I); AorTech Europe Ltd, Strathclyde, Scotland (Aspire AorTech).

\section{Surgical Intervention}

Mitral valve replacement. Operations occurred after achievement of general anesthesia. After a left thoracotomy was carried

TABLE 1. Chronically implanted bioprostheses: Valve and implant characteristics

\begin{tabular}{|c|c|c|c|c|c|c|c|c|c|}
\hline & & & & Implant & Valve size & Implant & uration & & \\
\hline & Design & Name & Age & position & (range) & $3 \mathrm{mo}$ & 5-6 mo & Treatment & Fixation \\
\hline Porcine & Stented & Mosaic (305) & A & $\mathrm{P}$ & 21 & $\mathrm{n}=3$ & $\mathrm{n}=3$ & $\mathrm{AOA}$ & $\mathrm{GA}$ \\
\hline & & Hancock MO & A & $P$ & $19-25$ & $n=3$ & $\mathrm{n}=3$ & None & $\mathrm{GA}$ \\
\hline & & Hancock II & A & M & 23 & & $n=5$ & SDS & GA \\
\hline & & Epic (ELS) & A & $P$ & $21-23$ & $\mathrm{n}=3$ & $\mathrm{n}=3$ & $\operatorname{Lin} x$ & GA \\
\hline & & Epic (ELS) & A & M & 23 & & $\mathrm{n}=3$ & $\operatorname{Lin} x$ & GA \\
\hline & & Labcor Duranol (TLPB-A) & A & $\mathrm{P}$ & 21 & & $\mathrm{n}=6$ & Octanediol & GA \\
\hline & & Labcor Duranol (TLPB-A) & A & M & 23 & $n=3$ & $\mathrm{n}=2$ & Octanediol & $\mathrm{GA}$ \\
\hline & & Labcor (4891-A/TLPB-A) & A & $P$ & $21-23$ & $\mathrm{n}=3$ & $n=5$ & None & $\mathrm{GA}$ \\
\hline & & Labcor (4891-A) & A & M & $23-25$ & & $\mathrm{n}=2$ & None & GA \\
\hline & & Biocor genetic (H3636) & A & $P$ & $21-23$ & $n=1$ & $n=3$ & None & GA \\
\hline & & Aspire AorTech (A-44) & A & M & 23 & $n=1$ & $n=5$ & None & GA \\
\hline & & Hancock I pulmonary valved conduit & J & $\mathrm{P}$ & 20 & & $\mathrm{n}=3$ & None & $\mathrm{GA}$ \\
\hline & Stentless & Freestyle aortic root & A & $P$ & $21-23$ & $\mathrm{n}=3$ & $\mathrm{n}=3$ & $\mathrm{AOA}$ & $\mathrm{GA}$ \\
\hline & & Prima Plus (2500 P) & A & $P$ & $21-23$ & $n=3$ & $\mathrm{n}=3$ & Tween 80 & GA \\
\hline & & Toronto SPV (SPA-101) & A & $\mathrm{P}$ & $19-22$ & $\mathrm{n}=9$ & $\mathrm{n}=3$ & None & $\mathrm{GA}$ \\
\hline & & Photofix & A & $\mathrm{P}$ & $21-23$ & $\mathrm{n}=3$ & $\mathrm{n}=2$ & None & DMPO \\
\hline & & Labcor pulmonary conduit (TO 7EAIS) & J & $\mathrm{P}$ & $15-17$ & & $\mathrm{n}=3$ & None & $\mathrm{GA}$ \\
\hline & & Biocor No-React I & A & $P$ & $21-23$ & $n=3$ & $\mathrm{n}=3$ & No react & None \\
\hline Pericardial & Stented & Perimount (2900) & A & $P$ & $21-23$ & $\mathrm{n}=3$ & $\mathrm{n}=3$ & Tween 80 & $\mathrm{GA}$ \\
\hline & & Perimount (2900) & A & M & 23 & $\mathrm{n}=2$ & $\mathrm{n}=3$ & Tween 80 & GA \\
\hline & & Pericarbon & A & $\mathrm{P}$ & $21-25$ & $n=3$ & $\mathrm{n}=3$ & None & $\mathrm{GA}$ \\
\hline & Stentless & Pericarbon & A & P & $19-23$ & $n=3$ & $\mathrm{n}=2$ & None & $\mathrm{GA}$ \\
\hline Total no. of & nimals & & & & & 120 & & & \\
\hline
\end{tabular}

Porcine, Porcine aortic tissue; Pericardium, bovine pericardial tissue; $A$, adolescent; $P$, pulmonary; $A O A, \alpha$-amino-oleic acid; $G A$, glutaraldehyde; $M$, mitral; $S D S$, sodium dodecylsulfate; Linx (manufactured by St Jude Medical, Inc, St Paul, Minn); J, juvenile; DMPO, dye-mediated photo-oxidation. 
out, the animals were started on cardiopulmonary bypass, and mitral valve replacement was performed. ${ }^{2}$

Pulmonary valve replacement. After achievement of general anesthesia and artificial ventilation, a left thoracotomy was carried out. After administration of heparin $(3 \mathrm{mg} / \mathrm{kg})$, a pneumatic right ventricular assist device (Medos HIA-VAD; Medos-Helmholtz Institute, Aachen, Germany) was installed, with the inflow cannula in the right atrium and the outflow cannula $1 \mathrm{~cm}$ proximal from the pulmonary bifurcation. The prosthetic valve was implanted as an interposition in the pulmonary artery. In this way stentless valves were placed into position as a whole root. The native pulmonary valve was destroyed by tearing 2 cusps, and then the right ventricular assist device was stopped and removed. ${ }^{3}$

After mitral or pulmonary valve replacement, removal of the cannulas, and careful hemostasis, the chest was closed in layers, with a chest drain in the left pleural space.

No inotropic drugs are used during the procedure. The animal was ventilated at all times. After extubation, the animals returned to the controlled animal facility, where the general health of the sheep was checked daily.

\section{Experimental Models}

The combination of animal age, implant position, type of valve design, and type of tissue resulted in the following experimental models: (1) adolescent, mitral, stented, porcine or pericardial; (2) adolescent, pulmonary, stented or stentless, porcine or pericardial; and (3) juvenile, pulmonary, stented or stentless, porcine.

\section{Echocardiography}

Transthoracic echocardiography was performed by an experienced echocardiographer. This included a description of heart valve motion from the prosthetic implant in the pulmonic or mitral position.

\section{Animal Death}

The animal was prepared and anesthetized as described above, administered heparin $(3 \mathrm{mg} / \mathrm{kg})$ intravenously, and killed with an overdose of a $\mathrm{KCl}$ solution administered intravenously, and the heart was removed. The implanted bioprosthesis was excised, and macroscopic and soft radiographic images were taken (Figure 1). The valves were analyzed as described below.

\section{Dissection of the Explanted Valve}

Three sections of the valve were obtained by severing the commissures, each containing a complete cusp and a wall portion. Metal parts of the stents were removed in case of stented valves. Then every section was divided into 2 equal parts (Figure 1, A). One part was used for histology (hematoxylin and eosin and Von Kossa staining, Figure 2), and the other part was used for calcium content determination after further sampling. The cusp portion was divided into 3 parts: the commissural area, basal part, and free edge (Figure 1, A, parts 1, 2, and 3). The wall portion was also divided into 2 parts: the inflow part and the outflow part (Figure 1, $A$, parts 4 and 5). This resulted in 9 cusp samples and 6 wall samples in every valve.

\section{Quantitative Calcium Determination}

After lyophilization, the tissue was pulverized and desiccated to constant weight in an oven. Pulverized tissue was diluted in $20 \%$
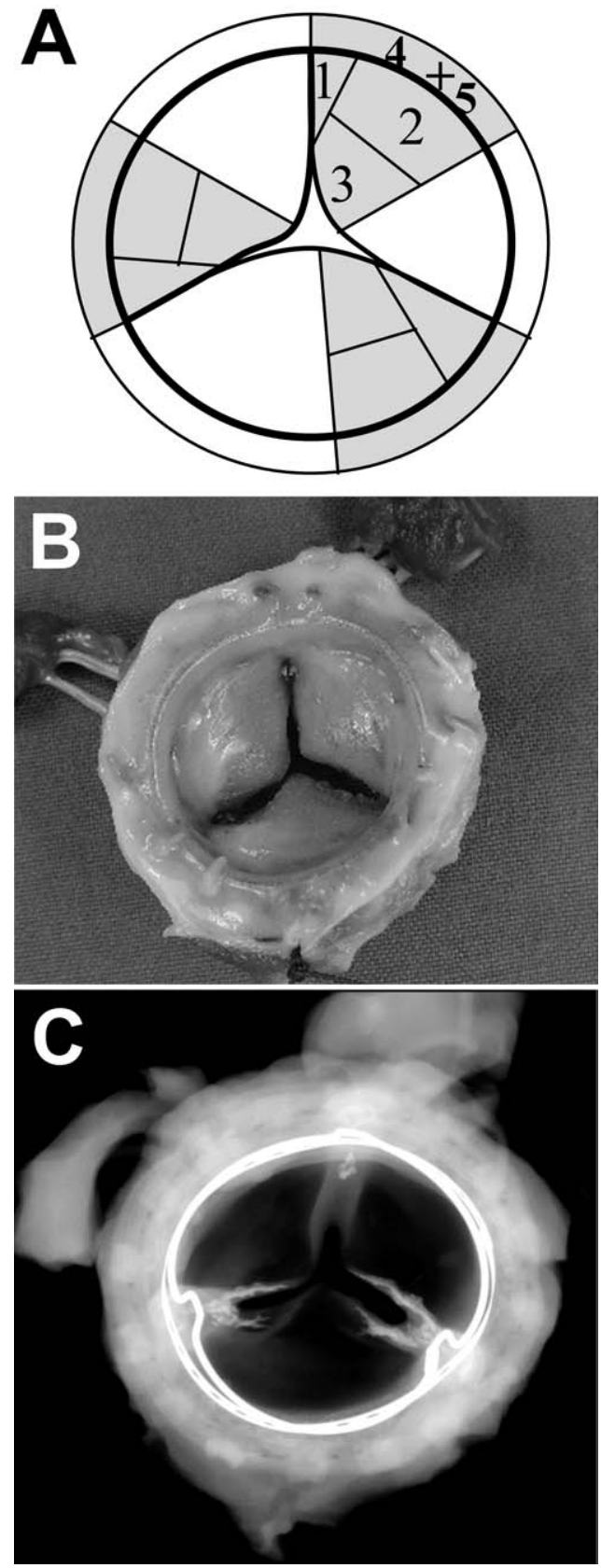

Figure 1. Illustration of macroscopic findings. A, Diagram demonstrating the dissection of the explanted valve for atomic absorption spectrometry measurements. By severing the commissures, the valve was divided into 3 parts, each containing a complete cusp and a wall portion. Half of each of the $\mathbf{3}$ segments (gray area) of the valve is used for quantitative calcium determination. The leaflet is divided into the commissural region (1), the basal portion (2), and the free edge (3). The wall is divided into the outflow (4) and inflow (5) portions. This results in 9 leaflet parts and 6 wall parts per valve. B, Gross pathology of an explanted Perimount valve. C, Radiograph of the same Perimount valve. Calcium is present at the commissures. 


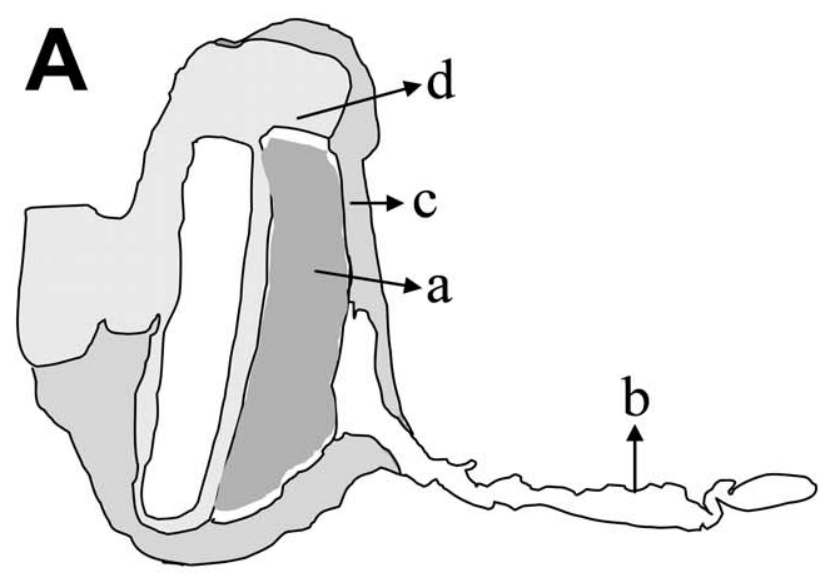

\section{B}

B

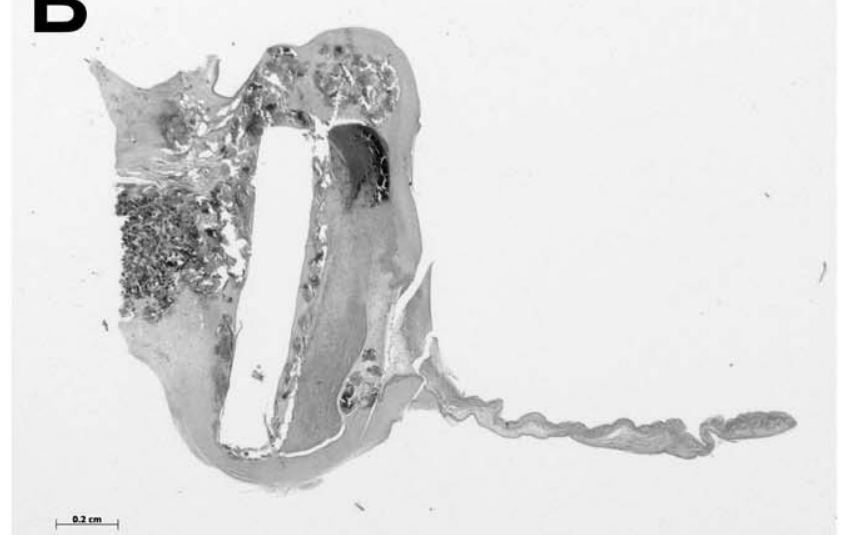

ram

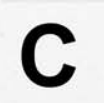

C

$102 \mathrm{~mm}$

Figure 2. Representative illustration of histologic findings. A, Diagram of longitudinal section through an explanted stented valve. $a$, Wall portion; $b$, leaflet; $c$, pannus overgrowth; $d$, Dacron cloth. B, Photomicrograph of hematoxylin and eosin-stained section of an explanted Aspire Aortech valve 6 months after implantation. C, Photomicrograph of Von Kossa-stained section. Calcium is visible at the top of the aortic wall portion and, to a lesser extent, around the suture near the annulus. hydrochloric acid at a ratio of $10 \mathrm{mg}$ of dried tissue to $1 \mathrm{~mL}$ of $\mathrm{HCl}$. Calcium content was measured by means of flame atomic absorption spectrometry and expressed in micrograms per milligram of dry weight.

Quantitative calcium content analysis was performed on about $50 \%$ of the valve tissue material, as described above.

Nonimplanted control valves. In 23 valves that were never implanted, calcium content was determined, as described above. This series included 345 samples originating from 2 Toronto, 1 Labcor Duranol, 2 Freestyle, 3 Epic, 2 Labcor, 2 Mosaic, 5 Pericarbon stented, 4 Perimount, and 2 Aspire Aortech valves.

Short-term implants. Six valves were recovered from animals that died early (1-5 days) after the operation: 1 Hancock II, 1 Aspire Aortech, 1 Toronto, and 3 Pericarbon stented valves. Calcium content was determined in a total of 90 samples.

Chronically implanted valves. A total of 120 chronically implanted valves (Table 1) were used in this study. Fifteen samples per valve were analyzed on calcium content, which resulted in 1721 values.

\section{Data Management and Statistical Analysis}

Normal probability plots (with the Shapiro-Wilks test for normality) were constructed to judge data distribution. Given the important skewed, nonnormal distribution of the calcium content data, logistic transformation was performed (Figure 3). Further statistical analysis consisted of multiple linear regression modeling with a backward stepwise selection technique after insertion of all variables with a univariate $P$ value of less than .1 (univariate analysis by $t$ tests).

Groupwise comparison of anticalcification treatments was performed on the original calcium content data by using nonparametric techniques (Kolmogorov-Smirnov testing, completed with separate Mann-Whitney $U$ tests). Consequently, when dealing with the original data, medians and interquartile ranges are used in the plots.

\section{Results}

\section{Mortality and Morbidity}

In total, 126 sheep underwent operations. Six animals died as a result of the surgical intervention (bleeding and low cardiac output) within 5 days postoperatively. The remaining 120 sheep having no clinical symptoms were nevertheless tested on silent endocarditis: sections of the explanted valves were stained (Gram-Pas-Grocott) for histologic diagnosis of tissue infection.

\section{Echocardiography}

All prosthetic valves functioned well at 1 week. There were no signs of valve thrombosis recorded. Also, at autopsy, there was no additional thrombus found in and around the native pulmonary valve, which was destroyed during the operation.

\section{Spacial Distribution of Valve Calcification}

When all the data obtained from explanted bioprostheses after chronic implantation are considered, calcification in 

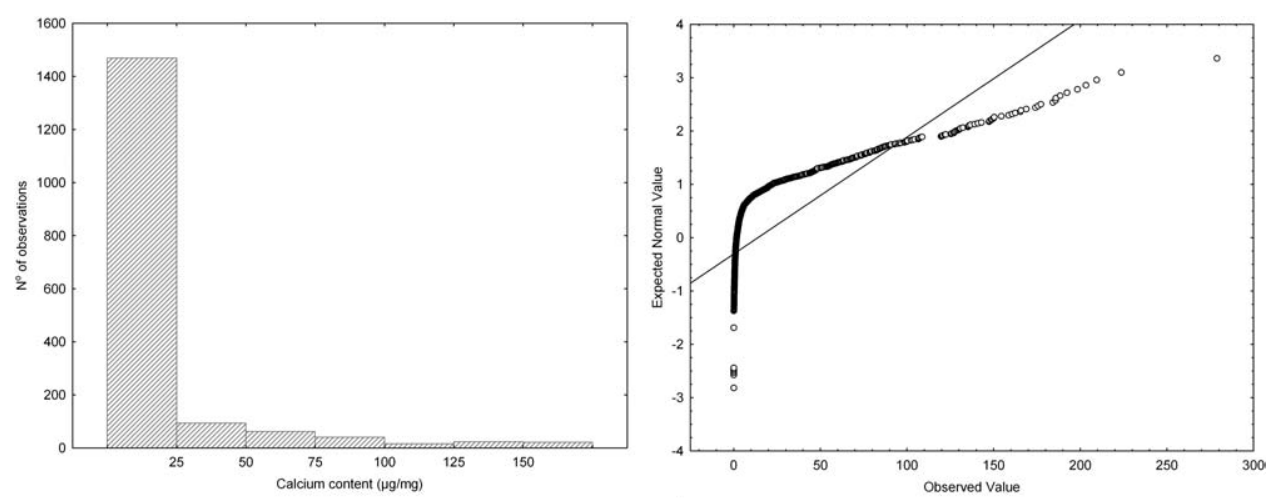

Figure 3. Distribution of calcium content data and concomitant normal probability plots. The upper panels show the extreme skew distribution of the calcium content data, with a strong deviation from a straight line in the normal probability plot. Logistic transformation of the original data results in a normal distribution (lower panels).
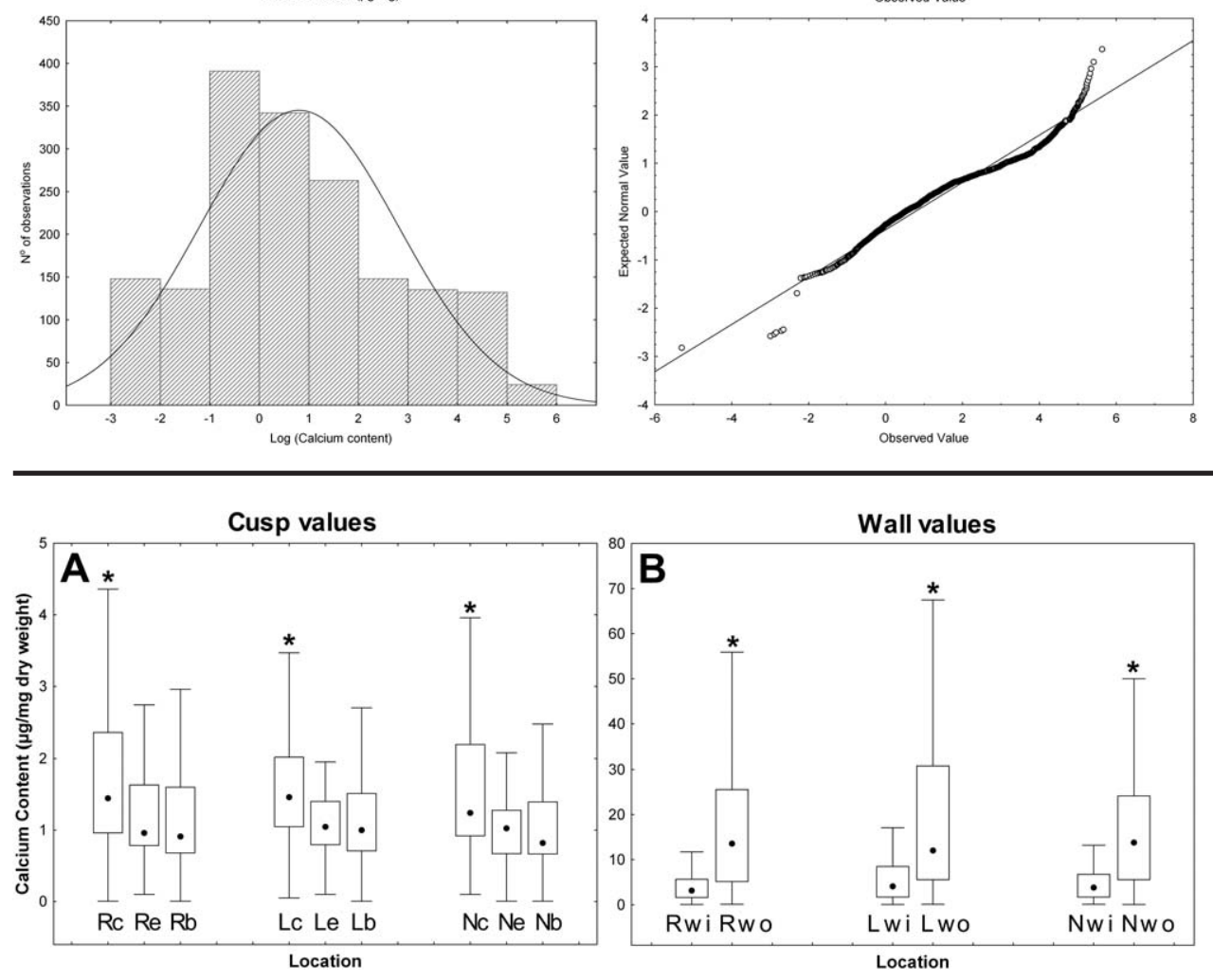

Figure 4. Spatial distribution of valve calcification. The graphs shows median values, with the interquartile range (rectangular box) and nonoutlier range (nonoutlier range $=$ all values of the $1.5 \times$ interquartile range interval). A, Calcium content in different cusp parts, separated for right, left, and noncoronary cusps. B, Calcium content in inflow and outflow parts of the wall portion of the prosthesis. Consistently higher values are seen in commissural parts and

in the outflow portion of the wall. ${ }^{*} \boldsymbol{P}<.002$. $R c$, Right coronary cusp commissure; $R e$, right coronary cusp free edge; $R b$, right coronary cusp base; $L c$, left coronary cusp commissure; $L e$, left coronary cusp free edge; $L b$, left coronary cusp base; $N c$, noncoronary cusp commissure; $\mathrm{Ne}$, noncoronary cusp free edge; $\mathbf{N b}$, noncoronary cusp base; Rwi, inflow part wall right coronary cusp; Rwo, outflow part wall right coronary cusp; Lwi, inflow part wall left coronary cusp; Lwo, outflow part wall left coronary cusp; Nwi, inflow part wall noncoronary cusp; Now, outflow part noncoronary cusp.

the cusps is significantly lower than in the aortic wall portions of the valve $(P<.001)$. Within the cusps, the highest calcium levels are found in the commissures, and the lowest calcium levels are found in the edges of the cusp. There is no prevalence for calcification between cusps (Figure $4, A$ ). In the wall portion of the valve, the highest values are found in the outflow part of the valve (Figure 4, B). The nature of the calcification was studied in the histologic sections. Extrinsic calcification was found in 9 of 120 valves and was located in the pannus formation at the base of the leaflets. This was found in 4 stentless valves (Biocor I, Prima plus, Toronto, and Pericarbon) and 5 stented valves (Labcor, Labcor Duranol, Mosaic, and 2 Pericarbon valves). All theses valves were implanted in the pulmonary position. All other calcifications were intrinsic calcifications. The differences in calcification between the porcine valve types are analyzed by using multiple comparisons, as presented in Table 2. It is shown that many valve types differ in their 
TABLE 2. Nonparametric comparison (Kruskal-Wallis) of all porcine valve types in the study (cusp values)

\begin{tabular}{|c|c|c|c|c|c|c|c|c|c|c|c|c|c|c|}
\hline & & $\begin{array}{c}\text { Hancock } \\
\text { NT }\end{array}$ & $\begin{array}{l}\text { Biocor } \\
\text { gen }\end{array}$ & Aspire & Labcor & $\begin{array}{l}\text { Lab } \\
\text { con }\end{array}$ & Toronto & $\begin{array}{c}\text { Hancock } \\
\text { II }\end{array}$ & Mosaic & $\begin{array}{l}\text { Lab } \\
\text { Dur }\end{array}$ & Epic & $\begin{array}{c}\text { Prima } \\
\text { Plus }\end{array}$ & Photofix & Freestyle \\
\hline \multirow{4}{*}{$\begin{array}{l}\text { Stented; } \\
\text { No Am }\end{array}$} & Hancock NT & & & & & & & & & & & & & \\
\hline & Biocor genetic & - & & & & & & & & & & & & \\
\hline & Aspire AorTech & $* * *$ & - & & & & & & & & & & & \\
\hline & Labcor & $* *$ & $* * *$ & $* * *$ & & & & & & & & & & \\
\hline \multirow{2}{*}{$\begin{array}{c}\text { Stentless; } \\
\text { No Am }\end{array}$} & Labcor $p$ conduit & $* * *$ & - & - & $* * *$ & & & & & & & & & \\
\hline & Toronto SPV & - & * & $* * *$ & - & $* * *$ & & & & & & & & \\
\hline \multirow{4}{*}{$\begin{array}{l}\text { Stented; } \\
\text { Am }\end{array}$} & Hancock II & - & - & - & $* * *$ & - & $* * *$ & & & & & & & \\
\hline & Mosaic & $* * *$ & $* * *$ & $* * *$ & - & $* * *$ & - & $* * *$ & & & & & & \\
\hline & Labcor Duranol & - & $* *$ & $* * *$ & - & $* * *$ & - & $* * *$ & - & & & & & \\
\hline & Epic & - & $* *$ & $* * *$ & - & $* * *$ & - & $* * *$ & - & - & & & & \\
\hline \multirow{4}{*}{$\begin{array}{l}\text { Stentless; } \\
\text { Am }\end{array}$} & Prima Plus & $* * *$ & $* * *$ & $* * *$ & - & $* * *$ & - & $* * *$ & - & - & - & & & \\
\hline & Photofix & $* * *$ & $* * *$ & $* * *$ & - & $* * *$ & $*$ & $* * *$ & - & - & - & - & & \\
\hline & Freestyle & $* * *$ & $* * *$ & $* * *$ & - & $* * *$ & - & $* * *$ & - & - & - & - & - & \\
\hline & Biocor No-React I & - & ** & $* * *$ & - & $* * *$ & - & $* * *$ & - & - & - & - & - & - \\
\hline
\end{tabular}

$A m$, Antimineralization treatment; $N T$, nontreated; Hancock $N T$, includes Hancock I valved conduit and Hancock M0; -, no significant difference. $* P<$ $.05, * * P<.01, * * * P<.001$.

TABLE 3. Univariate and multivariate analysis of calcium content data

\begin{tabular}{|c|c|c|c|c|c|c|c|c|}
\hline & \multicolumn{4}{|c|}{ Cusp } & \multicolumn{4}{|c|}{ Wall } \\
\hline & \multirow{2}{*}{$\begin{array}{c}\text { Univariate } \\
\text { analysis }\end{array}$} & \multicolumn{3}{|c|}{ Multivariate analysis } & \multirow{2}{*}{$\begin{array}{c}\begin{array}{c}\text { Univariate } \\
\text { analysis }\end{array} \\
P \text { value }\end{array}$} & \multicolumn{3}{|c|}{ Multivariate analysis } \\
\hline & & $\boldsymbol{\beta}$ & $P$ value & Level & & $\boldsymbol{\beta}$ & $P$ value & Level \\
\hline Implant duration (3 mo/6 mo) & $<.00001$ & -0.0328 & NS & $3 \mathrm{mo}=6 \mathrm{mo}$ & NS & & & $3 \mathrm{M} \mathrm{mo}=6 \mathrm{mo}$ \\
\hline Age (juvenile/ adolescent) & $<.00001$ & -0.3135 & $<.0001$ & $\mathrm{~A}<\mathrm{J}$ & $<.00001$ & -0.2084 & $<.0001$ & $\mathrm{~A}<\mathrm{J}$ \\
\hline Position (pulmonary/mitral) & $<.00001$ & -0.2591 & $<.0001$ & $\mathrm{P}<\mathrm{M}$ & .035 & 0.0632 & NS & $P=M$ \\
\hline Design (stented/stentless) & .0018 & 0.0502 & NS & $\mathrm{St}=\mathrm{SI}$ & .00004 & -0.1890 & $<.0001$ & $\mathrm{St}<\mathrm{SI}$ \\
\hline $\begin{array}{l}\text { Origin (porcine/bovine } \\
\text { pericardial) }\end{array}$ & $<.00001$ & 0.2309 & $<.0001$ & $\mathrm{PA}>\mathrm{BP}$ & $<.00001$ & 0.3757 & $<.0001$ & $\mathrm{PA}>\mathrm{BP}$ \\
\hline $\begin{array}{l}\text { Anticalcification treatment } \\
\text { (treated/nontreated) }\end{array}$ & .0011 & -0.1479 & $<.0001$ & $\mathrm{~T}<\mathrm{NT}$ & .0052 & -0.1363 & .0005 & $\mathrm{~T}<\mathrm{NT}$ \\
\hline
\end{tabular}

Tests used are $t$ tests and multiple linear regression with the logistically transformed calcium content data. For the cusp, all variables entered the multivariate model because all univariate $P$ values were smaller than .1. For the wall, the factor implant duration was excluded because of a lack of significance at the univariate level. The multivariate analysis for the cusp reveals the implant duration and the design as nonsignificant variables. For the wall, implant position is the only nonsignificant variable. All other variables are withheld as significant predictors for calcium content. The $\beta$ value indicates the magnitude of the effect. $N S$, not significant; $A$, adolescent; $J$, juvenile; $P$, pulmonary; $M$, mitral; $S t$, stented; $S I$, stentless; $P A$, porcine aorta; $B P$, bovine pericardium; $T$, treated; $N T$, nontreated.

calcium content, which might be related, in addition to the age of the sheep, to factors like fixation process, antimineralization treatment, and design. Indeed, these valves represent multiple generations of valves and valve design. To unravel the significance of the different factors influencing valve calcification, multiple types of valves were grouped together, and a univariate and multivariate analysis was performed by using the logistically transformed calcium content data.

\section{Factors Influencing Valve Calcification}

Univariate analysis revealed that calcium content is significantly $(P<.05)$ related to valve part or fraction (cusp or wall portion), age (juvenile or adolescent), tissue origin (porcine or pericardial), treatment (antimineralization treatment or not), implant position (mitral or pulmonary), tissue origin (porcine or pericardial), and valve design (stented or stentless). Extending the implantation duration from 3 to 6 months did not increase calcification further $(P>.05)$. For further univariate and multivariate analysis, cusp and wall portion data were separated (Table 3). Multivariate analysis of the cusp data reveals the following factors as independent predictors of calcification: age of the animal (adolescent $<$ juvenile), implant position (pulmonary $<$ mitral), tissue origin (pericardial $<$ porcine), and valve treatment (treated $<$ nontreated). Valve design (stented or stentless) and, again, long-term duration of implantation (3 or 6 months) is not a 
significant predictor. For the wall portion, age, tissue origin, design, and treatment are independent predictors of calcification $(P<.05)$, but position and implant duration are not $(P>.05)$.

Effect of implantation duration. In the not-implanted valves calcium content was $0.38 \pm 0.31 \mu \mathrm{g} / \mathrm{mg}$ for the leaflets, $0.38 \pm 0.30 \mu \mathrm{g} / \mathrm{mg}$ for the aortic wall portion $(P>$ $.05)$, and $0.38 \pm 0.30 \mu \mathrm{g} / \mathrm{mg}$ for the entire valve. There were no differences found in calcium content between types of valves $(P>.05)$. This resulted in an upper calcium limit of $1 \mu \mathrm{g} / \mathrm{mg}$ (mean value +2 standard deviations), indicating normal baseline calcium content of the valves before implantation.

These results were compared with those originating from valves that were implanted for only 1 to 5 days. Calcium content was significantly higher than in corresponding areas of similar types of nonimplanted valves: $1.47 \pm 0.85 \mu \mathrm{g} / \mathrm{mg}$ in the leaflets, $1.59 \pm 0.96 \mu \mathrm{g} / \mathrm{mg}$ in the wall portion, and $1.52 \pm 0.89 \mu \mathrm{g} / \mathrm{mg}$ in the entire valve $(P>.05)$.

In adolescent sheep the overall calcium content of valves increased about 10 times during the first 3 months of implantation (to $14.3 \mu \mathrm{g} / \mathrm{mg}$ ) but remained at this level during the next 3 months.

Juvenile versus adolescent sheep. As described above, multivariate analysis of the calcium content data revealed that age was a significant and independent factor of increased calcification for the cusp as for the aortic wall portion (Table 3). In an effort to quantify these calcification characteristics, calcium content was determined in all juvenile (5 months of age) and adolescent (11 months of age) sheep. The results are as follows: in juvenile sheep overall calcium content was several times higher than in adolescent sheep, in the leaflets (Figure 5, A) as in the aortic wall portion (Figure 6, A).

Implant position. Multivariate analysis of the data indicated that the position of valve implantation (mitral or pulmonary) is an independent factor of valve calcification, although only for the cusps. Calcification of the leaflets is significantly higher after mitral than after pulmonary implantation (Table 3). When the aortic wall portion is considered, no significant effect of implant position is found.

When the calcium contents at 3 to 6 months of all valves implanted in the pulmonary position are compared with those of all valves at the same time interval but implanted in the mitral position, calcium content of the leaflets was about twice as high in the mitral than in the pulmonary implants (Figure 5, B).

Valve design and tissue material. The multivariate analysis indicated that valve design (stented or stentless) and tissue material (pericardium or porcine aorta) are independent factors influencing calcification (Table 3). Stenting is only an independent predictor of wall calcification and not for cusp calcification, but tissue material is important for both wall and cusp calcification. When the results of all stented valves are compared with those of all stentless valves, stentless valves calcify more than stented valves in the wall portion (Figure 6, B). Valves constructed from pericardial tissue calcify less than valves made of porcine aortic roots. When all porcine valves are compared with all pericardial valves, calcium content is higher in the porcine valves compared with that in the pericardial valves, in the leaflets (Figure 5, C) as in the wall portion (Figure 6,C).

Antimineralization treatment. When the calcium content data of valves that received any kind of antimineralization treatment were compared with those of nontreated valves, a significantly lower calcification was found $(P<$ $.001)$. Multivariate analysis indicated that treatment was an independent factor influencing valve calcification (Table 3).

The following antimineralization treatments were included:

1. surfactants: sodium dodecylsulfate (SDS; Hancock II valve), polysorbate 80 (Tween 80: Perimount, Prima Plus valves), No-React (No-React: Biocor No-React I

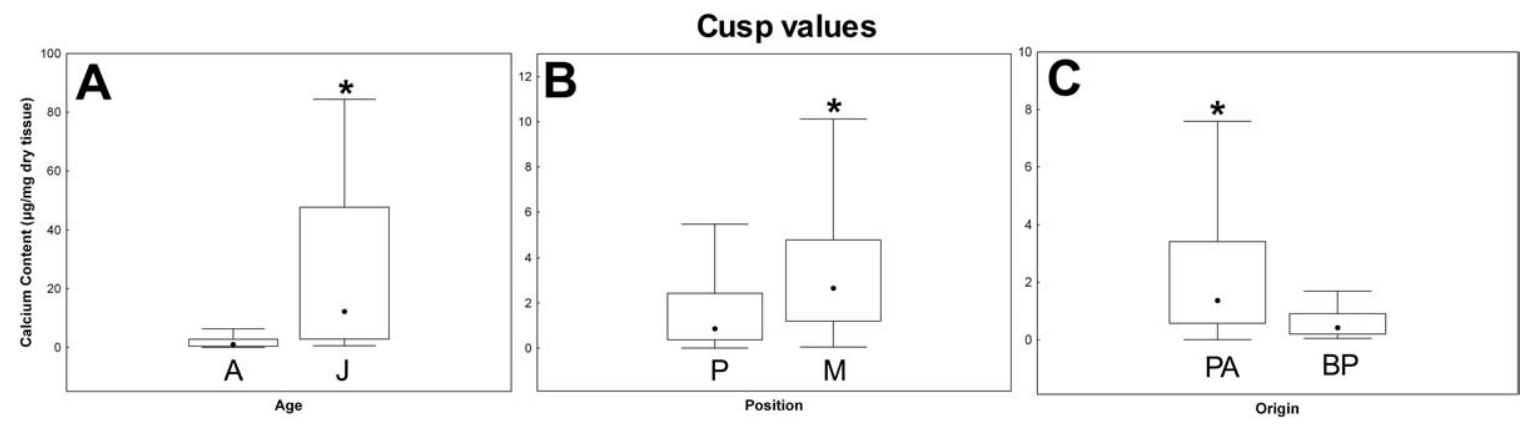

Figure 5. Calcium content values in the cusp. The graph shows median values, with the interquartile range (rectangular box) and nonoutlier range. A, Calcium content in cusps of adolescent $(A)$ and juvenile $(J)$ sheep. B, calcium content in pulmonary $(P)$ and mitral $(M)$ implanted cusps. $C$, Calcium content in porcine aortic $(P A)$ and bovine pericardial $(B P)$ cusps. ${ }^{*} P<.00001$. 


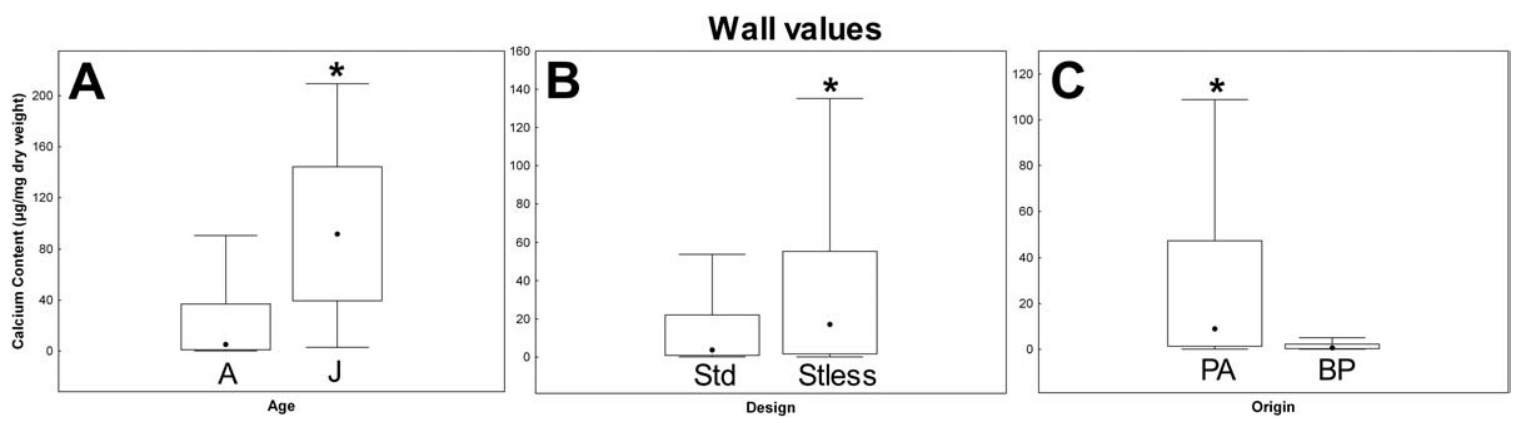

Figure 6. Calcium content values in the wall. The graph shows median values, with the interquartile range (rectangular box) and nonoutlier range. A, Calcium content in the wall of adolescent $(A)$ and juvenile $(J)$ sheep. $B$, Calcium content in the wall of stented (Std) and stentless (Sless) valves. C, Calcium content in porcine aortic $(P A)$ and bovine pericardial $(B P)$ wall. ${ }^{*} P<.0003$.
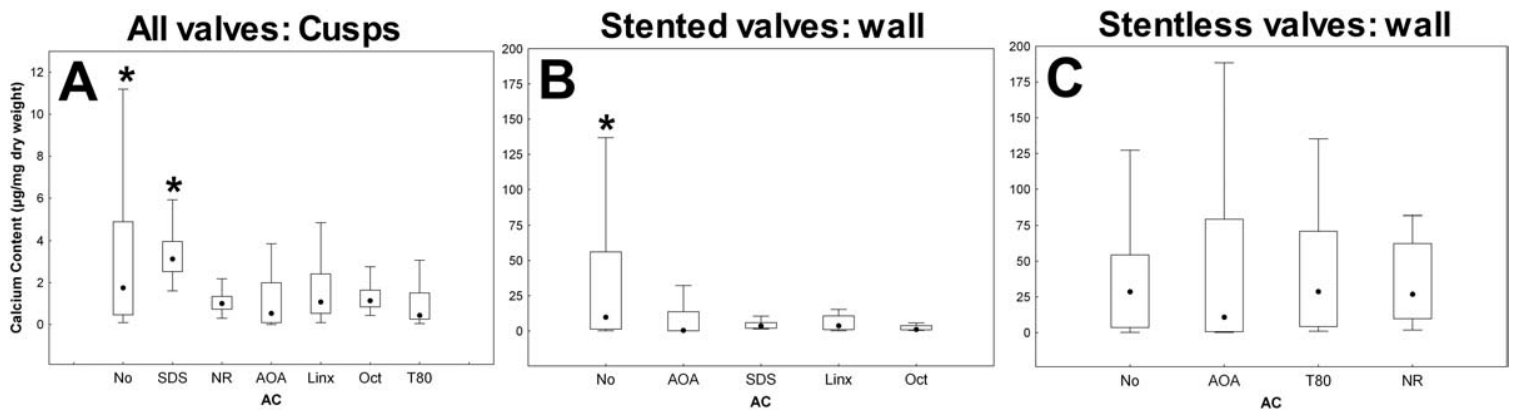

Figure 7. Calcium content values in valves treated with different anticalcification agents. The graph shows median values, with the interquartile range (rectangular box) and nonoutlier range. A, Calcium content in the cusps (all valves). Nontreated (No) and sodium dodecylsulfate (SDS)-treated valves have a significantly higher calcium content. B, Calcium content in the wall of stented valves. Nontreated valves have a significantly higher calcium content compared with valves treated with anticalcification agents. C, Calcium content in the wall of stentless valves. Significant differences between treatments are not found. ${ }^{*} P<.05$. A0A, $\alpha$-Amino-oleic acid Linx (St Jude Medical, Inc, St Paul, Minn).

valves), and $\alpha$-amino-oleic acid (AOA; Mosaic, Freestyle valves) and

2. alcohols: octanediol (Duranol: Labcor Duranol valve) and ethanol (Linx: Epic valve).

For the leaflets, any form of antimineralization treatment tested resulted in less calcification than the nonuse of treatment, except for SDS (Figure 7, A). Concerning the wall portion in stentless valves, no treatment had a significant effect in reducing calcification (Figure 7, C). In stented valves the limited wall portion that is present calcifies less when an antimineralization treatment is applied (Figure 7, B).

\section{Discussion}

This study shows that the calcification potential of adolescent sheep is considerable and not exclusive for juvenile animals. This can be related to the still-enhanced calcium metabolism in these young animals. ${ }^{4}$ Although the calcification potential in adolescent sheep is less than that in juvenile sheep, it is powerful enough to reveal the factors influencing calcification processes and to distinguish between the effects of different antimineralization treatments.

The finding that young age is an important determinant of tissue prosthesis calcification is not surprising. It has been long known from clinical implants that prosthetic valve calcification and its consequences are strongly related to patient age at implantation. ${ }^{5}$

It was, and perhaps still is, believed that pericardial and porcine tissue equally calcifies with time when used as a prosthetic construct. This originates from the finding that both tissues have the same potential for calcification when implanted subcutaneously in rats. This, however, does not imply that they, as valve constructs, will calcify to the same extent. Indeed, results from rats cannot be freely extrapolated to other species ${ }^{1}$ and certainly not when blood contact conditions are involved. ${ }^{6}$ Nevertheless, the extensive work in sheep from Jones and colleagues ${ }^{1}$ and Gallo and associ- 
ates ${ }^{7}$ could not differentiate between the calcification rates of porcine or pericardial valves. The problem is that a mixture of different porcine valves was compared with a mixture of different pericardial valves from different manufacturers. Recently, a sophisticated in vitro technique using holographic interferometry was developed to test tissue calcification. ${ }^{8}$ When comparing pericardial valves from one manufacturer with porcine bioprostheses from different manufacturers, no differences in calcification rates can be found. ${ }^{8}$ It was concluded that the biologic material of the prosthesis (pericardial or porcine) is not the crucial factor but that mechanical stresses have a much more pronounced effect on calcification. Nevertheless, using the same technology, Glasmacher and coworkers ${ }^{9}$ demonstrated that pericardial valves are less prone to calcification than porcine valves when valves from the same manufacturer are compared. Our findings in the present study suggest also that tissue source is an independent predictor of valve calcification in the sense that pericardial valves calcify less than porcine valves. This was confirmed by clinical data when the long-term performance of Carpentier-Edwards porcine bioprostheses and Carpentier-Edwards pericardial bioprostheses were compared. ${ }^{10}$ It was found that 10-year freedom from explantation was lower for the porcine $(90 \% \pm 2 \%)$ than for the pericardial $(97 \% \pm 2 \%, P=.04)$ valves. The incidence of structural valve degeneration was much higher in porcine than in pericardial valves.

This, however, does not mean that pericardial bioprostheses do not calcify: it was extensively shown in sheep ${ }^{1,7}$ and in human subjects ${ }^{11-13}$ that pericardial prostheses of different designs and from different manufacturers calcify at different rates. It has long been known that mechanical stress stimulates calcification, ${ }^{14}$ and it was clearly shown by Deiwick and colleagues ${ }^{8}$ that valve calcification strongly correlates with stress distribution within the valve. This explains the significant influence of valve design on valve calcification.

In the present study several aspects of this interrelationship among valve design, valve structure, and calcification characteristics come about in the adolescent sheep model. First, there is the distribution of valve calcification. We could clearly show that at sites of increased mechanical stress and strain, calcification was pronounced: predominantly at the cuspal commissures, to a lesser extent at the base of the leaflet, and in the least at the free edge. This is in agreement with the findings of Schoen and associates ${ }^{15}$ and demonstrates again the sensitivity of the adolescent sheep model.

Remarkable in our studies comparing stented with stentless valves ${ }^{16}$ was that the wall calcification occurs more progressively and more rapidly in stentless valves than in their stented counterparts. In previous studies we already focused attention on porcine wall mineralization of tissue valves and revealed an important cell-mediated calcification process. ${ }^{17}$ Besides the importance of dead cells and cell remnants as foci of early mineralization, the contribution of elastin, elastolysis, and subsequent calcification of elastic fibers in the aortic wall portion was shown. Thus in general the aortic wall calcifies more than the cusps, most probably because of its typical highly cellularized structure, which contains more elastin. Obviously, stenting in itself reduces aortic wall calcification, so that in stented valves the difference between cusp and wall calcification fades away or even reverses, especially after left-sided (mitral) valve implantation when increased stress accentuates cusp calcification. This might explain why Biedrzycki and associates ${ }^{18}$ found that calcification in the aortic wall segments of failed stented human porcine bioprostheses was approximately half that of cuspal calcification. All valves were failing in the aortic or mitral position and were heavily calcified $(66 \pm 6.3 \mu \mathrm{g} / \mathrm{mg})$. It was suggested by Trantina-Yates and coworkers ${ }^{19}$ that the predominant calcification of the aortic wall is species related and typical for sheep. They found a distinctly higher value of aortic wall calcification in the sheep model compared with that seen in nonhuman primates. The problem with this study is that the difference in aortic wall calcification can be age related rather than species related because the sheep were juveniles and the age of the baboons was unknown. Also, the finding that the aortic wall portion, mainly in stentless valves, calcifies more in the pulmonary position is confirmed by human data: allograft aortic valves or roots implanted in the right-sided circulation frequently fail because of calcific stenosis, often predominantly in the aortic wall portion. ${ }^{20}$ Midterm echocardiographic follow-up studies after Ross operations also have shown that homografts in the pulmonary position are prone to a calcification and stenotic process. Independent predictors of homograft failure in the pulmonary position were young age at the time of the operation and the use of aortic instead of pulmonary homografts. ${ }^{21}$

Schoen and colleagues ${ }^{22}$ suggested that the reduced aortic wall calcification in stented valves might be related to the fact that the stent with cloth might block diffusion of calcium-containing fluid from the adventitial side of the aortic wall. Another possibility is that the valve stent reduces mechanical stress on the small aortic wall segment, which was trimmed contiguous with the cusps to a level slightly distal to the commissures and incorporated into the prosthesis. Until now, there have been no available systematic data on calcification of explanted stentless valves in human subjects, which makes further comparison with the sheep model impossible.

Another independent factor that influences cusp and wall calcification is the implant position (left or right side). Prosthetic valve implantation in the left side of the heart (mitral position) accentuates calcification of the cusps, whereas right- 
sided implantation accentuates calcification of the wall portion. This was confirmed in human implants, ${ }^{18}$ with the highest calcium concentrations shown in the cusps in mitral valve implants.

In general, biologic tissue used in the construction of heart valve bioprostheses is glutaraldehyde treated to prevent degeneration of the material after implantation. However, glutaraldehyde treatment is related to in vivo calcification of the fixed tissue. Various preglutaraldehyde and postglutaraldehyde tissue treatments have been attempted to overcome these detrimental effects. These include detergents or surfactants, such as SDS and polysorbate 80 (Tween 80). Their mode of action is mainly related to removal of cellular remnants and phospholipids from the tissue, and their effect was first described in juvenile sheep by Jones and colleagues. ${ }^{1}$ One has to distinguish between the anticalcification effects of a given treatment on the leaflets or on the valve wall portion. On the leaflets, both the detergents and surfactants Tween 80, No-React, and AOA and the alcohols ethanol and octanediol have a similar effect as anticalcification agents. SDS had no effect on cusp protection (Figure $7, A)$. AOA, Tween 80, and No-React had no effect against aortic wall calcification in porcine stentless valves. In a previous study we could show that ethanol and AOA are superior to SDS as an antimineralization treatment. ${ }^{23}$ Whether the No-React process reduces calcification to the level of the detergents or of the more effective anticalcification treatments could not be determined from our adolescent sheep study. Because the mode of action of this procedure was never clarified, ${ }^{24}$ it is difficult to explore the real effects of these kinds of procedures.

In conclusion, we demonstrates that the adolescent sheep model is useful and sensitive in the study of bioprosthetic heart valve prostheses, provided sufficient animals are used to overcome variability in calcification data. Also, it became clear that optimal valve testing should take into account the different independent factors influencing bioprosthesis calcification. For example, valved conduits for right-sided implantation in congenital heart disease should be tested in juvenile sheep and in the pulmonary position, whereas stented bioprostheses can be tested preferentially in adolescent sheep in the mitral position.

\section{References}

1. Jones M, Eidbo EE, Hilbert SL, Ferrans VJ, Clark RE. The effects of anticalcification treatments on bioprosthetic heart valves implanted in sheep. ASAIO Trans. 1988;34:1027-30.

2. Gallo I, Frater RW. Experimental atrioventricular bioprosthetic valve insertion: a simple and successful technique. Thorac Cardiovasc Surg. 1983;31:288-90.

3. Herijgers P, Ozaki S, Verbeken E, Van Lommel A, Racz R, Zietkiewicz $\mathrm{M}$, et al. Calcification characteristics of porcine stentless valves in juvenile sheep. Eur J Cardiothorac Surg. 1999;15:134-42.
4. Braithwaite GD, Riazuddin S. The effect of age and level of dietary calcium intake on calcium metabolism in sheep. Br J Nutr. 1971;26: 215-25.

5. Bernal JM, Rabasa JM, Lopez R, Nistal JF, Muniz R, Revuelta JM. Durability of the Carpentier-Edwards porcine bioprosthesis: role of age and valve position. Ann Thorac Surg. 1995;60(suppl):S248-52.

6. Meuris B, Ozaki S, Herijgers P, Verbeken E, Flameng W. Bioprosthetic tissue calcification: influence of blood contact and arterial pressure: an experimental study in rats and sheep. J Heart Valve Dis. 2003;12:392-9.

7. Gallo I, Nistal F, Artinano E, Fernandez D, Cayon R, Carrion M, et al. The behavior of pericardial versus porcine valve xenografts in the growing sheep model. J Thorac Cardiovasc Surg. 1987;93:281-90.

8. Deiwick M, Glasmacher B, Tjan DT, Reul H, von Bally G, Scheld HH. Holographic interferometry and in vitro calcification: comparing pericardial versus porcine bioprostheses. J Heart Valve Dis. 1998;7:419-27.

9. Glasmacher B, Reul H, Schneppershoff S, Schreck S, Rau G. In vitro calcification of pericardial bioprostheses. J Heart Valve Dis. 1998;7: 415-8.

10. Gao G, Wu Y, Grunkemeier GL, Furnary AP, Starr A. Durability of pericardial versus porcine aortic valves. J Am Coll Cardiol. 2004;44: 384-8.

11. Valente M, Ius P, Bortolotti U, Talenti E, Bottio T, Thiene G. Pathology of the Pericarbon bovine pericardial xenograft implanted in humans. J Heart Valve Dis. 1998;7:180-9.

12. Machida H, Ishibashi-Ueda H, Nakano K, Sasako Y, Kobayashi J, Bando K, et al. A morphologic study of Carpentier-Edwards pericardial xenografts in the mitral position exhibiting primary tissue failure in adults in comparison with Ionescu-Shiley pericardial xenografts. J Thorac Cardiovasc Surg. 2001;122:649-55.

13. Le Tourneau T, Savoye C, McFadden EP, Grandmougin D, Carton HF, Hennequin JL, et al. Mid-term comparative follow-up after aortic valve replacement with Carpentier-Edwards and Pericarbon pericardial prostheses. Circulation. 1999;100(suppl):II11-6.

14. Thubrikar MJ, Deck JD, Aouad J, Nolan SP. Role of mechanical stress in calcification of aortic bioprosthetic valves. $J$ Thorac Cardiovasc Surg. 1983;86:115-25.

15. Schoen FJ, Levy RJ, Nelson AC, Bernhard WF, Nashef A, Hawley M. Onset and progression of experimental bioprosthetic heart valve calcification. Lab Invest. 1985;52:523-32.

16. Ozaki S, Herijgers P, Verbeken E, Van Lommel A, Nishida T, Perek $\mathrm{B}$, et al. The influence of stenting on the behavior of amino-oleic acid-treated, glutaraldehyde-fixed porcine aortic valves in a sheep model. J Heart Valve Dis. 2000;9:552-9.

17. Meuris B, Ozaki S, Herijgers P, Verbeken E, Flameng W. Influence of species, environmental factors, and tissue cellularity on calcification of porcine aortic wall tissue. Semin Thorac Cardiovasc Surg. 2001; 13(suppl 1):99-105.

18. Biedrzycki LM, Lerner E, Levy RJ, Schoen FJ. Differential calcification of cusps and aortic wall of failed stented porcine bioprosthetic valves. J Biomed Mater Res. 1997;34:411-5.

19. Trantina-Yates A, Weissenstein C, Human P, Zilla P. Stentless bioprosthetic heart valve research: sheep versus primate model. Ann Thorac Surg. 2001;71(suppl):S422-7.

20. Cleveland DC, Williams WG, Razzouk AJ, Trusler GA, Rebeyka IM, Duffy L, et al. Failure of cryopreserved homograft valved conduits in the pulmonary circulation. Circulation. 1992;86(suppl):II150-3.

21. Briand M, Pibarot P, Dumesnil JG, Cartier P. Midterm echocardiographic follow-up after Ross operation. Circulation. 2000;102(suppl 3):III10-4.

22. Schoen FJ, Hirsch D, Bianco RW, Levy RJ. Onset and progression of calcification in porcine aortic bioprosthetic valves implanted as orthotopic mitral valve replacements in juvenile sheep. $J$ Thorac Cardiovasc Surg. 1994;108:880-7.

23. Flameng WJ, Ozaki S, Yperman J, Herijgers P, Meuris B, Van Lommel A, et al. Calcification characteristics of porcine stented valves in a juvenile sheep model. Ann Thorac Surg. 2001;71(suppl):S401-5.

24. Abolhoda A, Yu S, Oyarzun JR, McCormick JR, Bogden JD, Gabbay S. Calcification of bovine pericardium: glutaraldehyde versus NoReact biomodification. Ann Thorac Surg. 1996;62:169-74. 